\title{
A Projection Method for Multiple Attribute Group Decision Making with Intuitionistic Fuzzy Information
}

\author{
Shouzhen $\mathrm{ZENG}^{1 *}$, Tomas BALEŽENTIS ${ }^{2}, \mathrm{Ji}_{\mathrm{CHEN}}{ }^{3}$, Gangfei LUO $^{3}$ \\ ${ }^{1}$ College of Compute and Information, Zhejiang Wanli University \\ Ningbo 315100, China \\ ${ }^{2}$ Lithuanian Institute of Agrarian Economics \\ V. Kudirkos Str. 18, LT-03105 Vilnius, Lithuania \\ ${ }^{3}$ College of Statistics and Mathematics, Zhejiang Gongshang University \\ Hangzhou 310018, China \\ e-mail:zszzxl@163.com,tomas@laei.lt,chenji810404@163.com,purityly@163.com
}

Received: September 2012; accepted: April 2013

\begin{abstract}
The aim of this paper is to investigate intuitionistic fuzzy multiple attribute group decision making problems where the attribute values provided by experts are expressed in intuitionistic fuzzy numbers, and the weight information about the experts is to be determined. We present a new method to derive the weights of experts and rank the preference order of alternatives based on projection models. We first derive the weights of the decision makers according to the projection of the individual decision on the ideal decision. The expert has a large weight if his evaluation value is close to the ideal decision, and has a small weight if his evaluation value is far from the ideal decision. Then, based on the weighted projection of the alternatives on the intuitionistic fuzzy ideal solution (IFIS), we develop a straightforward and practical algorithm to rank alternatives. Furthermore, we extend the developed model and algorithm to the multiple attribute group decision making problems with interval-valued intuitionistic fuzzy information. Finally, an illustrative example is given to verify the developed approach and to demonstrate its practicality and effectiveness.
\end{abstract}

Key words: intuitionistic fuzzy set, interval-valued intuitionistic fuzzy set, projection method, multiple attribute group decision making.

\section{Introduction}

Multiple attribute group decision making problems are those of major importance in diverse fields such as engineering, economics, and management. The current socioeconomic environment is becoming more and more complex, which makes it almost impossible for a single decision maker to consider all the aspects of a problem (Liou and Tzeng, 2012). Generally, several decision makers are involved in the decision making. In the process of decision making, the decision information about alternatives is usually uncertain or fuzzy due to the increasing complexity of the socio-economic environment and

\footnotetext{
${ }^{*}$ Corresponding author.
} 
the vagueness of inherent subjective nature of human thinking. The intuitionistic fuzzy set (IFS) (Atanassov, 1986, 1999), characterized by a membership function and a nonmembership function, is more suitable for dealing with fuzziness and uncertainty than the ordinary fuzzy set developed by Zadeh (1965) whose basic component is only a membership function. Gau and Buehrer (1993) gave the notion of vague set, which is another generalization of fuzzy sets. Bustince and Burillo (1996), nevertheless, showed that it is an equivalent of the IFS. Consider that, sometimes, it is not approximate to assume that the membership degrees for certain elements of an IFS are exactly defined, but a value range can be given. In such cases, Atanassov and Gargov (1989) introduced the notion of interval-valued intuitionistic fuzzy set (IVIFS), which is characterized by a membership function and a nonmembership function, whose values are intervals rather than exact numbers.

The IFS and IVIFS are highly useful in dealing with fuzziness and uncertainty, and thus, recently many researchers have applied them to the complex decision making problems. Some methods have been developed to solve the single person multiple attribute decision making problems with the IFS and IVIFS information (Grzegorzewski, 2004; Liu and Wang, 2007; Lin et al., 2007; Gong et al., 2009; Li, 2004, 2008, 2011; Wei, 2008, 2010a; Xu, 2007a, 2007b; Xu and Yager, 2008; Zhao et al., 2010; Lakshmana Gomathi Nayagam and Geetha, 2011; Wanga et al., 2011; Ye, 2009, 2010). On multi-person multi-attribute decision making, alternatively called multi-attribute group decision making (MAGDM, for short) problems, Mitchell (2004) defined an intuitionistic OWA operator which aggregates a set of intuitionistic fuzzy sets and described a simple application of the new intuitionistic OWA operator in multiple-expert multi-criteria decision making. Atanassov et al. (2005) provided a tool to solve the multi-person multi-criteria decision making problems, in which the attribute weights are given as exact numerical values and the attribute values are expressed in intuitionistic fuzzy numbers. $\mathrm{Xu}$ and Yager (2006) developed some geometric aggregation operators, such as the intuitionistic fuzzy weighted geometric (IFWG) operator, the intuitionistic fuzzy ordered weighted geometric (IFOWG) operator, and the intuitionistic fuzzy hybrid geometric (IFHG) operator and gave an application of the IFHG operator to MAGDM with intuitionistic fuzzy information. $\mathrm{Xu}$ (2007c) investigated the group decision making problems in which all the information provided by the decision makers is expressed as intuitionistic fuzzy decision matrices where each of the elements is characterized by intuitionistic fuzzy number, and the information about attribute weights is partially known. Xu (2007d) developed an approach to group decision making based on intuitionistic preference relations. $\mathrm{Xu}$ and Yager (2009) developed a new similarity measure and apply the developed similarity measure to the consensus analysis in group decision making based on intuitionistic fuzzy preference relations. Boran et al. (2009) combined TOPSIS method with IFS to select appropriate supplier in group decision making environment. Li et al. (2009) developed a new methodology based on some fractional programming models and the ranking method for solving MAGDM problems using ntuitionistic fuzzy sets (IFSs). Li et al. (2010) developed a linear programming methodology for solving MAGDM problems using IFSs. Yue et al. (2009) introduced an approach for aggregating multiple attribute values characterized by precise numerical values into an intuitionistic fuzzy number and gave an 
application of this fusion to MAGDM. Wei (2010b) developed the induced intuitionistic fuzzy ordered weighted geometric (IIFOWG) operator, and presented its application to MAGDM problems. Xu (2010a) utilized distance measures to solve MAGDM problems with interval-valued intuitionistic fuzzy information. Xu (2010b) investigated the MAGDM with intuitionistic fuzzy information and information about attribute weights is completely known or completely unknown, and proposed a deviation-based approach to solve the problems. Xu and Wang (2012) presented the induced generalized intuitionistic fuzzy ordered weighted averaging (IGIFOWA) operator and applied it to MAGDM problems concerning with searching the best global supplier. Zeng and Su (2011) and Zeng (in press) presented an intuitionistic fuzzy ordered weighted distance (IFOWD) operator, and applied it to group decision making. In all these literature, the weights of the decision makers (or experts) are determined beforehand. At present, many methods have been proposed to determine the weights of experts in intuitionistic fuzzy multiple attribute group decision making problems. Tan (2011) determined the decision makers' weights by the means of the Choquet integral. Xu and Cai (2010) developed some nonlinear optimization models to get the decision makers' weights. Yue (2011a) developed a new approach for measuring the decision makers' weights in group decision making setting based on distance measure, in which the decision information is expressed in interval-valued intuitionistic fuzzy numbers. Yue (2011b) presented an approach for group decision making based on determining weights of experts using TOPSIS method. Recently, Yue (2012a) introduced an approach for group decision making based on determining the weights of experts by using projection method. Yue (2012b) also developed a projection method for determining weights of DMs with interval numbers. Wang et al. (2009) investigated the group decision making problems in featuring incompletely known weights of the attributes and decision makers, which may be constructed by employing intuitionistic fuzzy numbers (IFNs). In all these existing approaches, the weights of the experts are the same for all the attributes. However, if the weights of experts for all the attributes are the same, the evaluating result would be unreasonable. Hence, the different weights of the decision makers should be assigned to different attributes in the group decision making problem, as different experts have their own knowledge and experience in reality and they are actually experts in some of the attributes and not in other attributes. Inspired by this idea, in this paper, we propose a projection method to derive experts' weights in IFSs and IVIFSs MAGDM through aggregating the individual decision matrices into a collective decision matrix. Especially, the expert whose evaluation value is close to the ideal decision has a large weight, while the expert whose evaluation value is far from the ideal decision would have a small weight. Further, the preference order of alternatives can be ranked in accordance with the projections of alternatives onto the ideal solution.

The rest of the paper is organized as follows. In Section 2, we give some basic concepts. In Section 3, we propose a straightforward and practical method to derive the weights of experts and rank the preference order of alternatives based on projection models. In Section 4, we extend the developed models and procedures to handle the MAGDM problems with interval-valued intuitionistic fuzzy information. In Section 5, we illustrate our proposed algorithmic method with an example. The final section concludes. 


\section{Preliminaries}

Atanassov introduced the concept of intuitionistic fuzzy set (IFS), which was defined as follows:

Let a set $X$ be fixed, an intuitionistic fuzzy set $A$ in $X$ is an object having the following form:

$$
A=\left\{\left\langle x, \mu_{A}(x), v_{A}(x)\right\rangle \mid x \in X\right\}
$$

where the functions $\mu_{A}(x): X \rightarrow[0,1]$ and $v_{A}(x): X \rightarrow[0,1]$ determine the degree of membership and the degree of non-membership of the element $x \in X$, such that $0 \leqslant$ $\mu_{A}(x)+v_{A}(x) \leqslant 1$ for all $x \in X$. In addition $\pi_{A}(x)=1-\mu_{A}(x)-v_{A}(x)$ is called the degree of indeterminacy of $x$ to $A$, or called the degree of hesitancy of $x$ to A. Especially, if $\pi_{A}(x)=0$, for all $x \in X$, then the IFS $A$ is reduced to a fuzzy set.

For convenience, the $\alpha=\left(\mu_{\alpha}, v_{\alpha}, \pi_{\alpha}\right)$ is called the intuitionistic fuzzy number (IFN) (Xu, 2007a; Xu and Yager, 2009), where

$$
\mu_{\alpha} \in[0,1], \quad v_{\alpha} \in[0,1], \quad \mu_{\alpha}+v_{\alpha} \leqslant 1, \quad \pi_{\alpha}=1-\mu_{\alpha}-v_{\alpha}
$$

and denote the module of $\alpha$ as:

$$
|\alpha|=\sqrt{\mu_{\alpha}^{2}+v_{\alpha}^{2}+\pi_{\alpha}^{2}} .
$$

Definition 1. (See $\mathrm{Xu}$ and $\mathrm{Hu}, 2010$.) Let $X=\left\{x_{1}, x_{2}, \ldots, x_{n}\right\}$ be a finite universe of discourse, $A$ be an IFS in $X$, then

$$
|A|=\sqrt{\sum_{i=1}^{n}\left|\alpha_{i}\right|^{2}}
$$

is called the module of $A$, where $\alpha_{i}=\left(\mu_{\alpha_{i}}, v_{\alpha_{i}}, \pi_{\alpha_{i}}\right)$ is the $i$-th IFN of $A$.

In many situations, the weight of the element $x_{j} \in X$ should be taken into account, for example, in multiple attribute decision making, the considered attributes usually have different importance, and thus need to be assigned with different weights. $\mathrm{Xu}$ and $\mathrm{Hu}$ (2010) defined the weighted module as follows.

Definition 2. Let $X=\left\{x_{1}, x_{2}, \ldots, x_{n}\right\}$ be a finite universe of discourse, $A$ be an IFS in $X$, then

$$
|A|_{w}=\sqrt{\sum_{i=1}^{n}\left(w_{i}\left|\alpha_{i}\right|\right)^{2}}
$$

is called the weighted module of $A$, where $\alpha_{i}=\left(\mu_{\alpha_{i}}, v_{\alpha_{i}}, \pi_{\alpha_{i}}\right)$ is the $i$-th IFN of $A$, and $w=\left(w_{1}, w_{2}, \ldots, w_{n}\right)$ is the weighting vector of $x_{j}(j=1,2, \ldots, n)$ with $w_{j} \in[0,1]$, $\sum_{j=1}^{n} w_{j}=1$. 
Definition 3. (See $\mathrm{Xu}$ and $\mathrm{Hu}, 2010$.) Let $X=\left\{x_{1}, x_{2}, \ldots, x_{n}\right\}$ be a finite universe of discourse, $A$ and $B$ be two IFSs in $X$, then

$$
\operatorname{Pr} j_{B} A=\frac{1}{|B|} \sum_{i=1}^{n}\left(\mu_{\alpha_{i}} \mu_{\beta_{i}}+v_{\alpha_{i}} v_{\beta_{i}}+\pi_{\alpha_{i}} \pi_{\beta_{i}}\right)
$$

is called the projection of $A$ on $B$, where $\alpha_{i}=\left(\mu_{\alpha_{i}}, v_{\alpha_{i}}, \pi_{\alpha_{i}}\right)$ and $\beta_{i}=\left(\mu_{\beta_{i}}, v_{\beta_{i}}, \pi_{\beta_{i}}\right)$ are the $i$-th IFNs of $A$ and $B$, respectively. Obviously, the greater the value $\operatorname{Pr} j_{B} A$, the more the degree of the $A$ approaching to the $B$. Especially, if $n=1$, then we get the the projection of IFN $\alpha_{1}=\left(\mu_{\alpha_{1}}, v_{\alpha_{1}}, \pi_{\alpha_{1}}\right)$ on $\beta_{1}=\left(\mu_{\beta_{1}}, v_{\beta_{1}}, \pi_{\beta_{1}}\right)$ as:

$$
\operatorname{Pr} j_{\beta_{1}} \alpha_{1}=\frac{1}{\left|\beta_{1}\right|}\left(\mu_{\alpha_{1}} \mu_{\beta_{1}}+v_{\alpha_{1}} v_{\beta_{1}}+\pi_{\alpha_{1}} \pi_{\beta_{1}}\right) .
$$

Definition 4. (See $\mathrm{Xu}$ and $\mathrm{Hu}, 2010$.) Let $X=\left\{x_{1}, x_{2}, \ldots, x_{n}\right\}$ be a finite universe of discourse, $A$ and $B$ be two IFSs in $X$, then

$$
\operatorname{Pr} j_{B} A=\frac{1}{|B|_{w}} \sum_{i=1}^{n} w_{i}^{2}\left(\mu_{\alpha_{i}} \mu_{\beta_{i}}+v_{\alpha_{i}} v_{\beta_{i}}+\pi_{\alpha_{i}} \pi \beta_{\beta_{i}}\right)
$$

is called the weighted projection of $A$ on $B$, where $\alpha_{i}=\left(\mu_{\alpha_{i}}, v_{\alpha_{i}}, \pi_{\alpha_{i}}\right)$ and $\beta_{i}=$ $\left(\mu_{\beta_{i}}, v_{\beta_{i}}, \pi_{\beta_{i}}\right)$ are the $i$-th IFNs of $A$ and $B$, respectively. $w=\left(w_{1}, w_{2}, \ldots, w_{n}\right)$ is the weighting vector of $x_{j}(j=1,2, \ldots, n)$ with $w_{j} \in[0,1], \sum_{j=1}^{n} w_{j}=1$.

\section{Multiple Attribute Group Decision Making Based on Intuitionistic Fuzzy Sets}

In the multiple attribute group decision making, decision makers first determine the evaluation values of the alternatives with respect to attributes. With these evaluation values, decision makers select the best alternative or rank the alternatives. During the decision process, several experts are involved in order to get a reasonable result. In the existing group decision making problems, the weights of the decision makers or experts are often determined beforehand. Usually, they have the same weight for all the attributes. But in some real-life situations, some decision makers are familiar with some of the attributes, but not others due to any activities requiring human expertise and knowledge, which are inevitably imprecise or not totally reliable. When evaluating attributes they are not good at, experts may provide unreasonable values. The result would be unreasonable if the weights of experts for all the attributes are the same. On the other hand, if we assign different expert weights to different attributes, the additional amount of work would be too large. In this section, instead of assigning the weights of experts, we develop a projection model to derive weights of the experts from the evaluation values. The expert whose evaluation value is close to the ideal decision should be assigned a large weight, while the expert whose evaluation value is far from the ideal decision would have a small weight. 
For a group decision making problem, let $A=\left\{A_{1}, A_{2}, \ldots, A_{m}\right\}$ be a finite set of alternatives, $D=\left\{D_{1}, D_{2}, \ldots, D_{t}\right\}$ be the set of decision makers (or experts), $G=$ $\left\{G_{1}, G_{2}, \ldots, G_{n}\right\}$ be the set of attributes, and $w=\left(w_{1}, w_{2}, \ldots, w_{n}\right)$ be the weighting vector of the attributes, here $w_{j} \in[0,1], \sum_{j=1}^{n} w_{j}=1$. An intuitionistic fuzzy decision ma$\operatorname{trix} R^{(k)}=\left(r_{i j}^{(k)}\right)_{m \times n}=\left(t_{i j}^{(k)}, f_{i j}^{(k)}, \pi_{i j}^{(k)}\right)_{m \times n}$, whose elements $\left(t_{i j}^{(k)}, f_{i j}^{(k)}, \pi_{i j}^{(k)}\right)$ are IFNs, is provided by the decision maker $D_{k}$ for the alternative $A_{i}$ with respect to the attribute $G_{j}$. Here, given by the decision maker $D_{k}, t_{i j}^{(k)}$ indicates the degree that the alternative $A_{i}$ should satisfy the the attribute $G_{j}, f_{i j}^{(k)}$ indicates the degree that the alternative $A_{i}$ should not satisfy the attribute $G_{j}$ and $\pi_{i j}^{(k)}$ indicates the degree that the alternative $A_{i}$ is indeterminacy to the attribute $G_{j}$, and

$$
\begin{aligned}
& t_{i j}^{(k)}, f_{i j}^{(k)}, \pi_{i j}^{(k)} \in[0,1], \quad t_{i j}^{(k)}+f_{i j}^{(k)}+\pi_{i j}^{(k)}=1, \\
& \quad i=1,2, \ldots, m, j=1,2, \ldots, n .
\end{aligned}
$$

If all the attributes $G_{j}(j=1,2, \ldots, n)$ are of the same type, then the attribute values do not need normalization. Whereas, there are generally benefit attributes (the bigger the attribute values the better) and cost attributes (the smaller the attribute values the better) in MAGDM. In such cases, we may transform the attribute values of cost type into the attribute values of benefit type, then $R^{(k)}=\left(r_{i j}^{(k)}\right)_{m \times n}$ can be transformed into the intuitionistic fuzzy decision matrices $D^{(k)}=\left(d_{i j}^{(k)}\right)_{m \times n}$, where

$$
\begin{aligned}
d_{i j}^{(k)} & =\left(\mu_{i j}^{(k)}, v_{i j}^{(k)}, \pi_{i j}^{(k)}\right) \\
& = \begin{cases}\left(t_{i j}^{(k)}, f_{i j}^{(k)}, \pi_{i j}^{(k)}\right), & \text { for benefit attribute } G_{j}, \quad j=1,2, \ldots, n . \\
\left(f_{i j}^{(k)}, t_{i j}^{(k)}, \pi_{i j}^{(k)}\right), & \text { for cost attribute } G_{j},\end{cases}
\end{aligned}
$$

Suppose that the evaluation values for the alternative $A_{i}$ with respect to the attribute $G_{j}$ are $d_{i j}^{(1)}=\left(\mu_{i j}^{(1)}, v_{i j}^{(1)}, \pi_{i j}^{(1)}\right), d_{i j}^{(2)}=\left(\mu_{i j}^{(2)}, v_{i j}^{(2)}, \pi_{i j}^{(2)}\right), \ldots, d_{i j}^{(t)}=\left(\mu_{i j}^{(t)}, v_{i j}^{(t)}, \pi_{i j}^{(t)}\right)$ provided by $t$ experts. We define the mean of these evaluation values as $d_{i j}^{*}=\left(\mu_{i j}^{*}, v_{i j}^{*}, \pi_{i j}^{*}\right)$, where

$$
\mu_{i j}^{*}=\frac{1}{t} \sum_{k=1}^{t} \mu_{i j}^{(k)}, \quad v_{i j}^{*}=\frac{1}{t} \sum_{k=1}^{t} v_{i j}^{(k)}, \quad \pi_{i j}^{*}=\frac{1}{t} \sum_{k=1}^{t} \pi_{i j}^{(k)} .
$$

Inspired by compromise elements in the literature (Yue, 2011a, 2011b, 2012), the mean value $d_{i j}^{*}=\left(\mu_{i j}^{*}, v_{i j}^{*}, \pi_{i j}^{*}\right)$ can be defined as the ideal decision of all these evaluation values $d_{i j}^{(k)}(k=1,2, \ldots, t)$. In this sense, the more the degree that $d_{i j}^{(k)}$ is closer to the $d_{i j}^{*}$, the better the decision $d_{i j}^{(k)}$. Therefore, we can calculate the projection of each evaluation value on the ideal decision $d_{i j}^{*}$ by (7):

$$
\operatorname{Pr} j_{i j}^{*} d_{i j}^{(k)}=\frac{1}{\left|d_{i j}^{*}\right|}\left(\mu_{i j}^{(k)} \mu_{i j}^{*}+v_{i j}^{(k)} v_{i j}^{*}+\pi_{i j}^{(k)} \pi_{i j}^{*}\right) .
$$


Then the weight for $d_{i j}^{(k)}$ can be defined as:

$$
w_{i j}^{(k)}=\frac{\operatorname{Pr} j_{d_{i j}^{*}} d_{i j}^{(k)}}{\sum_{k=1}^{t} \operatorname{Pr} j_{d_{i j}^{*} d_{i j}^{(k)}}}, \quad k=1,2, \ldots, t, i=1,2, \ldots, m, j=1,2, \ldots, n .
$$

The weight of each expert determined by this model has the following desirable characteristic: the closer an evaluation value is to the the mean value, the larger the weight is. In this algorithm, the experts' weights are different for different attributes. This can avoid the unreasonable evaluation value induced by decision makers' limited knowledge or experience

When the weight values for the experts are determined, the evaluating values provided by different experts can be aggregated by using the weighted averaging operator:

$$
d_{i j}=w_{i j}^{(1)} d_{i j}^{(1)}+w_{i j}^{(2)} d_{i j}^{(2)}+\cdots+w_{i j}^{(t)} d_{i j}^{(t)} .
$$

Therefore, we can obtain the collective decision matrix $D=\left(d_{i j}\right)_{m \times n}$.

In the following, we will propose a procedure for MAGMD problems with intuitionistic fuzzy information by application of projection models. The procedure involves the following steps:

\section{Algorithm 1}

Step 1. The decision makers evaluate the alternatives with respect to the attributes to form the intuitionistic fuzzy decision matrices. Determine the expert weights for each evaluation value by (12) and (13), and aggregate the different experts' evaluations into a collective one by (14).

Step 2. Calculate the intuitionistic fuzzy ideal solution (IFIS): $A^{*}=\left(\alpha_{1}^{*}, \alpha_{2}^{*}, \ldots, \alpha_{n}^{*}\right)$, where $\alpha_{j}^{*}=\left(\mu_{j}^{*}, v_{j}^{*}, \pi_{j}^{*}\right)$ is IFN, and

$$
\begin{aligned}
\mu_{j}^{*} & =\max _{i}\left\{\mu_{i j}\right\}, \quad v_{j}^{*}=\min _{i}\left\{v_{i j}\right\}, \quad \pi_{j}^{*}=1-\mu_{j}^{*}-v_{j}^{*}, \\
i & =1,2, \ldots, m, j=1,2, \ldots, n
\end{aligned}
$$

Step 3. Utilize (8) to calculate the weighted projection of the alternative $A_{i}(i=$ $1,2, \ldots, m)$ on the IFIS $A^{*}$, that is

$$
\operatorname{Pr} j_{A^{*}} A_{i}=\frac{1}{\left|A^{*}\right|_{w}} \sum_{j=1}^{n} w_{j}^{2}\left(\mu_{i j} \mu_{j}^{*}+v_{i j} v_{j}^{*}+\pi_{i j} \pi_{j}^{*}\right) .
$$

Step 4. Rank all the alternatives $A_{i}(i=1,2, \ldots, m)$ in accordance with the projection $\operatorname{Pr} j_{A^{*}} A_{i}$. Obviously, the larger the projection $\operatorname{Pr} j_{A^{*}} A_{i}$, the closer the alternative $A_{i}$ is to the IFIS $A^{*}$, and the better the alternative, $A_{i}$. The above method employs only the projection models and the weighted averaging operator to aggregate evaluation information, therefore it is very simple and convenient to use in practical applications. 
In what follows, we shall extend the developed methods to the MAGDM with the interval-valued intuitionistic fuzzy information.

\section{Multiple Attribute Group Decision Making Based on Interval-Valued Intuitionistic Fuzzy Sets}

Interval-valued intuitionistic fuzzy set (IVIFS) was first introduced by Atanassov and Gargov (1989). It is characterized by an interval-valued membership degree and an intervalvalued non-membership degree. Let a set $X$ be fixed, an IVIFS in $X$ is an object of the following form

$$
\tilde{A}=\left\{\left\langle x, \tilde{\mu}_{\tilde{A}}(x), \tilde{v}_{\tilde{A}}(x)\right\rangle \mid x \in X\right\}
$$

where $\tilde{\mu}_{\tilde{A}}(x)=\left[\tilde{\mu}_{\tilde{A}}^{L}(x), \tilde{\mu}_{\tilde{A}}^{U}(x)\right] \subset[0,1]$ and $\tilde{v}_{\tilde{A}}(x)=\left[\tilde{v}_{\tilde{A}}^{L}(x), \tilde{v}_{\tilde{A}}^{U}(x)\right] \subset[0,1]$ are intervals, $\tilde{\mu}_{\tilde{A}}^{L}(x)=\inf \tilde{\mu}_{\tilde{A}}(x), \tilde{\mu}_{\tilde{A}}^{U}(x)=\sup \tilde{\mu}_{\tilde{A}}(x), \tilde{v}_{\tilde{A}}^{L}(x)=\inf \tilde{v}_{\tilde{A}}(x), \tilde{v}_{\tilde{A}}^{U}(x)=\sup \tilde{v}_{\tilde{A}}(x)$, and

$$
\tilde{\mu}_{\tilde{A}}^{U}(x)+\tilde{v}_{\tilde{A}}^{U}(x) \leqslant 1, \quad \text { for all } x \in X .
$$

Let $\tilde{\pi}_{\tilde{A}}(x)=\left[\tilde{\pi}_{\tilde{A}}^{L}(x), \tilde{\pi}_{\tilde{A}}^{U}(x)\right]$, where

$$
\tilde{\pi}_{\tilde{A}}^{L}(x)=1-\tilde{\mu}_{\tilde{A}}^{U}(x)-\tilde{v}_{\tilde{A}}^{U}(x), \quad \tilde{\pi}_{\tilde{A}}^{U}(x)=1-\tilde{\mu}_{\tilde{A}}^{L}(x)-\tilde{v}_{\tilde{A}}^{L}(x), \quad \text { for all } x \in X .
$$

Especially, if $\tilde{\mu}_{\tilde{A}}(x)=\tilde{\mu}_{\tilde{A}}^{L}(x)=\tilde{\mu}_{\tilde{A}}^{U}(x)$ and $\tilde{v}_{\tilde{A}}(x)=\tilde{v}_{\tilde{A}}^{L}(x)=\tilde{v}_{\tilde{A}}^{U}(x)$, then $\tilde{A}$ is reduced to an IFS.

The pair $\left(\tilde{\mu}_{\tilde{A}}\left(x_{i}\right), \tilde{v}_{\tilde{A}}\left(x_{i}\right), \tilde{\pi}_{\tilde{A}}\left(x_{i}\right)\right)$ is called an interval-valued intuitionistic fuzzy number (IVIFN) (Xu and Yager, 2009). For convenience, we denote an IVIFN by $\tilde{\alpha}=$ $\left(\tilde{\mu}_{\tilde{\alpha}}, \tilde{v}_{\tilde{\alpha}}, \tilde{\pi}_{\tilde{\alpha}}\right)$, where

$$
\begin{aligned}
& \tilde{\mu}_{\tilde{\alpha}}=\left[\tilde{\mu}_{\tilde{\alpha}}^{L}, \tilde{\mu}_{\tilde{\alpha}}^{U}\right] \in[0,1], \quad \tilde{v}_{\tilde{\alpha}}=\left[\tilde{v}_{\tilde{\alpha}}^{L}, \tilde{v}_{\tilde{\alpha}}^{U}\right] \in[0,1], \quad \tilde{\mu}_{\tilde{\alpha}}^{U}+\tilde{v}_{\tilde{\alpha}}^{U} \leqslant 1, \\
& \tilde{\pi}_{\tilde{\alpha}}=\left[\tilde{\pi}_{\tilde{\alpha}}^{L}, \tilde{\pi}_{\tilde{\alpha}}^{U}\right]=\left[1-\tilde{\mu}_{\tilde{\alpha}}^{U}-\tilde{v}_{\tilde{\alpha}}^{U}, 1-\tilde{\mu}_{\tilde{\alpha}}^{L}-\tilde{v}_{\tilde{\alpha}}^{L}\right] .
\end{aligned}
$$

Definition 5. (See $\mathrm{Xu}$ and $\mathrm{Hu}, 2010$.) Let $X=\left\{x_{1}, x_{2}, \ldots, x_{n}\right\}$ be a finite universe of discourse, $\tilde{A}$ be an IVIFS in $X$, then

$$
|\tilde{A}|=\sqrt{\sum_{i=1}^{n}\left|\tilde{\alpha}_{i}\right|^{2}}
$$


is called the module of $\tilde{A}$, where $\tilde{\alpha}_{i}=\left(\tilde{\mu}_{\tilde{\alpha}_{i}}, \tilde{v}_{\tilde{\alpha}_{i}}, \tilde{\pi}_{\tilde{\alpha}_{i}}\right)$ is the $i$-th IVIFN of $\tilde{A}$, and $\left|\tilde{\alpha}_{i}\right|$ is the module of $\tilde{\alpha}_{i}$, which can be denoted as follows:

$$
\left|\tilde{\alpha}_{i}\right|=\sqrt{\left(\tilde{\mu}_{\tilde{\alpha}_{i}}^{L}\right)^{2}+\left(\tilde{\mu}_{\tilde{\alpha}_{i}}^{U}\right)^{2}+\left(\tilde{v}_{\tilde{\alpha}_{i}}^{L}\right)^{2}+\left(\tilde{v}_{\tilde{\alpha}_{i}}^{U}\right)^{2}+\left(\tilde{\pi}_{\tilde{\alpha}_{i}}^{L}\right)^{2}+\left(\tilde{\pi}_{\tilde{\alpha}_{i}}^{U}\right)^{2}} .
$$

Definition 6. (See Xu and Hu, 2010.) Let $X=\left\{x_{1}, x_{2}, \ldots, x_{n}\right\}$ be a finite universe of discourse, $\tilde{A}$ be an IVIFS in $X$, then

$$
|\tilde{A}|_{w}=\sqrt{\sum_{i=1}^{n}\left(w_{i}\left|\tilde{\alpha}_{i}\right|\right)^{2}}
$$

is called the weighted module of $\tilde{A}$, where $\tilde{\alpha}_{i}=\left(\tilde{\mu}_{\tilde{\alpha}_{i}}, \tilde{v}_{\tilde{\alpha}_{i}}, \tilde{\pi}_{\tilde{\alpha}_{i}}\right)$ is the $i$-th IVIFN of $\tilde{A}$, and $w=\left(w_{1}, w_{2}, \ldots, w_{n}\right)$ is the weighting vector of $x_{j}(j=1,2, \ldots, n)$ with $w_{j} \in[0,1]$, $\sum_{j=1}^{n} w_{j}=1$.

Definition 7. (See Xu and Hu, 2010.) Let $X=\left\{x_{1}, x_{2}, \ldots, x_{n}\right\}$ be a finite universe of discourse, $\tilde{A}$ and $\tilde{B}$ be two IVIFSs in $X$, then

$$
\operatorname{Pr} j_{\tilde{B}} \tilde{A}=\frac{\sum_{i=1}^{n}\left(\tilde{\mu}_{\alpha_{i}}^{L} \tilde{\mu}_{\beta_{i}}^{L}+\tilde{\mu}_{\alpha_{i}}^{U} \tilde{\mu}_{\beta_{i}}^{U}+\tilde{v}_{\alpha_{i}}^{L} \tilde{v}_{\beta_{i}}^{L}+\tilde{v}_{\alpha_{i}}^{U} \tilde{v}_{\beta_{i}}^{U}+\tilde{\pi}_{\alpha_{i}}^{L} \tilde{\pi}_{\beta_{i}}^{L}+\tilde{\pi}_{\alpha_{i}}^{U} \tilde{\pi}_{\beta_{i}}^{U}\right)}{|\tilde{B}|}
$$

is called the projection of $\tilde{A}$ on $\tilde{B}$, where $\tilde{\alpha}_{i}=\left(\tilde{\mu}_{\tilde{\alpha}_{i}}, \tilde{v}_{\tilde{\alpha}_{i}}, \tilde{\pi}_{\tilde{\alpha}_{i}}\right)$ and $\tilde{\beta}_{i}=\left(\tilde{\mu}_{\tilde{\beta}_{i}}, \tilde{v}_{\tilde{\beta}_{i}}, \tilde{\pi}_{\tilde{\beta}_{i}}\right)$ are the $i$-th IVIFNs of $\tilde{A}$ and $\tilde{B}$, respectively. Obviously, the greater the value $\operatorname{Pr} j_{\tilde{B}} \tilde{A}$, the more the degree of the $\tilde{A}$ approaching to the $\tilde{B}$. Especially, if $n=1$, then we get the the projection of IVIFN $\tilde{\alpha}_{1}=\left(\tilde{\mu}_{\tilde{\alpha}_{1}}, \tilde{v}_{\tilde{\alpha}_{1}}, \tilde{\pi}_{\tilde{\alpha}_{1}}\right)$ on $\tilde{\beta}_{1}=\left(\tilde{\mu}_{\tilde{\beta}_{1}}, \tilde{v}_{\tilde{\beta}_{1}}, \tilde{\pi}_{\tilde{\beta}_{1}}\right)$ as:

$$
\operatorname{Pr} j_{\tilde{\beta}_{1}} \tilde{\alpha}_{1}=\frac{1}{\left|\tilde{\beta}_{1}\right|}\left(\tilde{\mu}_{\alpha_{1}}^{L} \tilde{\mu}_{\beta_{1}}^{L}+\tilde{\mu}_{\alpha_{1}}^{U} \tilde{\mu}_{\beta_{1}}^{U}+\tilde{v}_{\alpha_{1}}^{L} \tilde{v}_{\beta_{1}}^{L}+\tilde{v}_{\alpha_{1}}^{U} \tilde{\beta}_{\beta_{1}}^{U}+\tilde{\pi}_{\alpha_{1}}^{L} \tilde{\pi}_{\beta_{1}}^{L}+\tilde{\pi}_{\alpha_{1}}^{U} \tilde{\pi}_{\beta_{1}}^{U}\right) .
$$

Definition 8. (See Xu and Hu, 2010.) Let $X=\left\{x_{1}, x_{2}, \ldots, x_{n}\right\}$ be a finite universe of discourse, $\tilde{A}$ and $\tilde{B}$ be two IVIFSs in $X$, then

$$
\operatorname{Pr} j_{\tilde{B}} \tilde{A}=\frac{\sum_{i=1}^{n} w_{i}^{2}\left(\tilde{\mu}_{\alpha_{i}}^{L} \tilde{\mu}_{\beta_{i}}^{L}+\tilde{\mu}_{\alpha_{i}}^{U} \tilde{\mu}_{\beta_{i}}^{U}+\tilde{v}_{\alpha^{\prime}}^{L} \tilde{v}_{\beta_{i}}^{L}+\tilde{v}_{\alpha_{i}}^{U} \tilde{v}_{\beta_{i}}^{U}+\tilde{\pi}_{\alpha_{i}}^{L} \tilde{\pi}_{\beta_{i}}^{L}+\tilde{\pi}_{\alpha_{i}}^{U} \tilde{\pi}_{\beta_{i}}^{U}\right)}{|\tilde{B}|_{w}}
$$

is called the weighted projection of $\tilde{A}$ on $\tilde{B}$, where $\tilde{\alpha}_{i}=\left(\tilde{\mu}_{\tilde{\alpha}_{i}}, \tilde{v}_{\tilde{\alpha}_{i}}, \tilde{\pi}_{\tilde{\alpha}_{i}}\right)$ and $\tilde{\beta}_{i}=$ $\left(\tilde{\mu}_{\tilde{\beta}_{i}}, \tilde{v}_{\tilde{\beta}_{i}}, \tilde{\pi}_{\tilde{\beta}_{i}}\right)$ are the $i$-th IVIFNs of $\tilde{A}$ and $\tilde{B}$, respectively. $w=\left(w_{1}, w_{2}, \ldots, w_{n}\right)$ is the weighting vector of $x_{j}(j=1,2, \ldots, n)$ with $w_{j} \in[0,1], \sum_{j=1}^{n} w_{j}=1$.

We consider the same decision making problem as that in the Section 3. But now the evaluation value of the alternative $A_{i}$ with respect to the attribute $G_{j}$ is represented by the IVIFNs. Let $\tilde{R}^{(k)}=\left(\tilde{r}_{i j}^{(k)}\right)_{m \times n}=\left(\tilde{t}_{i j}^{(k)}, \tilde{f}_{i j}^{(k)}, \tilde{\pi}_{i j}^{(k)}\right)_{m \times n}$ be an interval-valued intuitionistic 
fuzzy decision matrix. $\left(\tilde{t}_{i j}^{(k)}, \tilde{f}_{i j}^{(k)}, \tilde{\pi}_{i j}^{(k)}\right)$ is the corresponding IVIFN provided by the decision maker maker $D_{k}$ for the alternative $A_{i}$ with respect to the attribute $G_{j}$. Here, $\tilde{t}_{i j}^{(k)}$ indicates the degree that the alternative $A_{i}$ should satisfy the the attribute $G_{j}, \tilde{f}_{i j}^{(k)}$ indicates the degree that the alternative $A_{i}$ should not satisfy the attribute $G_{j}$ and $\tilde{\pi}_{i j}^{(k)}$ indicates the degree that the alternative $A_{i}$ is indeterminacy to the attribute $G_{j}$, for convenience of calculation, let $\tilde{t}_{i j}^{(k)}=\left[\tilde{t}_{i j}^{L(k)}, \tilde{t}_{i j}^{U(k)}\right], \tilde{f}_{i j}^{(k)}=\left[\tilde{f}_{i j}^{L(k)}, \tilde{f}_{i j}^{U(k)}\right], \tilde{\pi}_{i j}^{(k)}=\left[\tilde{\pi}_{i j}^{L(k)}, \tilde{\pi}_{i j}^{U(k)}\right]$, and

$$
\begin{aligned}
& {\left[\tilde{t}_{i j}^{L(k)}, \tilde{t}_{i j}^{U(k)}\right] \subset[0,1], \quad\left[\tilde{f}_{i j}^{L(k)}, \tilde{f}_{i j}^{U(k)}\right] \subset[0,1], \quad \tilde{t}_{i j}^{U(k)}+\tilde{f}_{i j}^{U(k)} \leqslant 1,} \\
& \tilde{\pi}_{i j}^{L(k)}=1-\tilde{t}_{i j}^{U(k)}-\tilde{f}_{i j}^{U(k)}, \quad \tilde{\pi}_{i j}^{U(k)}=1-\tilde{t}_{i j}^{L(k)}-\tilde{f}_{i j}^{L(k)}, \\
& \quad i=1,2, \ldots, m ; j=1,2, \ldots, n .
\end{aligned}
$$

In the cases where the attributes are of benefit and cost types, we normalize $\tilde{R}^{(k)}=$ $\left(\tilde{r}_{i j}^{(k)}\right)_{m \times n}$ into the interval intuitionistic fuzzy decision matrices $\tilde{D}^{(k)}=\left(\tilde{d}_{i j}^{(k)}\right)_{m \times n}$, where

$$
\begin{aligned}
\tilde{d}_{i j}^{(k)} & =\left(\tilde{\mu}_{i j}^{(k)}, \tilde{v}_{i j}^{(k)}, \tilde{\pi}_{i j}^{(k)}\right)=\left(\left[\tilde{\mu}_{i j}^{L(k)}, \tilde{\mu}_{i j}^{U(k)}\right],\left[\tilde{v}_{i j}^{L(k)}, \tilde{v}_{i j}^{U(k)}\right],\left[\tilde{\pi}_{i j}^{L(k)}, \tilde{\pi}_{i j}^{U(k)}\right]\right) \\
& = \begin{cases}\left(\tilde{t}_{i j}^{(k)}, \tilde{f}_{i j}^{(k)}, \tilde{\pi}_{i j}^{(k)}\right), & \text { for benefit attribute } G_{j}, \quad j=1,2, \ldots, n . \\
\left(\tilde{f}_{i j}^{(k)}, \tilde{t}_{i j}^{(k)}, \tilde{\pi}_{i j}^{(k)}\right), & \text { for cost attribute } G_{j},\end{cases}
\end{aligned}
$$

Suppose that the evaluation values for the alternative $A_{i}$ with respect to the attribute $G_{j}$ are $\tilde{d}_{i j}^{(1)}=\left(\tilde{\mu}_{i j}^{(1)}, \tilde{v}_{i j}^{(1)}, \tilde{\pi}_{i j}^{(1)}\right), \tilde{d}_{i j}^{(2)}=\left(\tilde{\mu}_{i j}^{(2)}, \tilde{v}_{i j}^{(2)}, \tilde{\pi}_{i j}^{(2)}\right), \ldots, \tilde{d}_{i j}^{(t)}=\left(\tilde{\mu}_{i j}^{(t)}, \tilde{v}_{i j}^{(t)}, \tilde{\pi}_{i j}^{(t)}\right)$ provided by $t$ experts. We define the mean of these evaluation values as $\tilde{d}_{i j}^{*}=\left(\tilde{\mu}_{i j}^{*}, \tilde{v}_{i j}^{*}, \tilde{\pi}_{i j}^{*}\right)=$ $\left(\left[\tilde{\mu}_{i j}^{L *}, \tilde{\mu}_{i j}^{U *}\right],\left[\tilde{v}_{i j}^{L *}, \tilde{v}_{i j}^{U *}\right],\left[\tilde{\pi}_{i j}^{L *}, \tilde{\pi}_{i j}^{U *}\right]\right)$, where

$$
\begin{aligned}
& \tilde{\mu}_{i j}^{L *}=\frac{1}{t} \sum_{k=1}^{t} \tilde{\mu}_{i j}^{L(k)}, \quad \tilde{\mu}_{i j}^{U *}=\frac{1}{t} \sum_{k=1}^{t} \tilde{\mu}_{i j}^{U(k)}, \quad \tilde{v}_{i j}^{L *}=\frac{1}{t} \sum_{k=1}^{t} \tilde{v}_{i j}^{L(k)}, \\
& \tilde{v}_{i j}^{U *}=\frac{1}{t} \sum_{k=1}^{t} \tilde{v}_{i j}^{U(k)}, \quad \tilde{\pi}_{i j}^{L *}=\frac{1}{t} \sum_{k=1}^{t} \tilde{\pi}_{i j}^{L(k)}, \quad \tilde{\pi}_{i j}^{U *}=\frac{1}{t} \sum_{k=1}^{t} \tilde{\pi}_{i j}^{U(k)} .
\end{aligned}
$$

The projection of each evaluation value $\tilde{d}_{i j}^{(k)}$ on the mean value $\tilde{d}_{i j}^{*}$ is defined as follows:

$$
\begin{aligned}
& \operatorname{Pr} j_{\tilde{d}_{i j}^{*}} \tilde{d}_{i j}^{(k)} \\
& =\frac{\left(\tilde{\mu}_{i j}^{L(k)} \tilde{\mu}_{i j}^{L *}+\tilde{\mu}_{i j}^{U(k)} \tilde{\mu}_{i j}^{U *}+\tilde{v}_{i j}^{L(k)} \tilde{v}_{i j}^{L *}+\tilde{v}_{i j}^{U(k)} \tilde{v}_{i j}^{U *}+\tilde{\pi}_{i j}^{L(k)} \tilde{\pi}_{i j}^{L *}+\tilde{\pi}_{i j}^{U(k)} \tilde{\pi}_{i j}^{U *}\right)}{\left|\tilde{d}_{i j}^{*}\right|} .
\end{aligned}
$$


Therefore, the weight for $\tilde{d}_{i j}^{(k)}$ can be defined as follows:

$$
w_{i j}^{(k)}=\frac{\operatorname{Pr} j_{\tilde{d}_{i j}^{*}} \tilde{d}_{i j}^{(k)}}{\sum_{k=1}^{t} \operatorname{Pr} j_{\tilde{d}_{i j}^{*}} \tilde{d}_{i j}^{(k)}}, \quad k=1,2, \ldots, t, i=1,2, \ldots, m, j=1,2, \ldots, n
$$

After obtaining these weights, we can aggregate the evaluation values provided by different experts through

$$
\tilde{d}_{i j}=w_{i j}^{(1)} \tilde{d}_{i j}^{(1)}+w_{i j}^{(2)} \tilde{d}_{i j}^{(2)}+\cdots+w_{i j}^{(t)} \tilde{d}_{i j}^{(t)}
$$

where $\tilde{d}_{i j}=\left(\tilde{\mu}_{i j}, \tilde{v}_{i j}, \tilde{\pi}_{i j}\right)=\left(\left[\tilde{\mu}_{i j}^{L}, \tilde{\mu}_{i j}^{U}\right],\left[\tilde{v}_{i j}^{L}, \tilde{v}_{i j}^{U}\right],\left[\tilde{\pi}_{i j}^{L}, \tilde{\pi}_{i j}\right]\right)$, thus, we can obtain the desired collective decision matrix $\tilde{D}=\left(\tilde{d}_{i j}\right)_{m \times n}$.

Similar to Section 3, a procedure for solving the above problems with interval-valued intuitionistic fuzzy information by application of projection method can be described as follows:

\section{Algorithm 2}

Step 1. The decision makers evaluate the alternatives with respect to the attributes to form the interval-valued intuitionistic fuzzy decision matrices. Determine the expert weights for each evaluation value by (30) and (31), and aggregate the different experts' evaluations into a collective one by (32).

Step 2. Calculate the uncertain intuitionistic fuzzy ideal solution (UIFIS): $\tilde{A}^{*}=$ $\left(\tilde{\alpha}_{1}^{*}, \tilde{\alpha}_{2}^{*}, \ldots, \tilde{\alpha}_{n}^{*}\right)$, where $\tilde{\alpha}_{j}^{*}=\left(\tilde{\mu}_{j}^{*}, \tilde{v}_{j}^{*}, \tilde{\pi}_{j}^{*}\right)$ is IVIFN, and

$$
\begin{aligned}
\tilde{\mu}_{j}^{*} & =\left[\tilde{\mu}_{j}^{L *}, \tilde{\mu}_{j}^{U *}\right]=\left[\max _{i}\left\{\tilde{\mu}_{i j}^{L}\right\}, \max _{i}\left\{\tilde{\mu}_{i j}^{U}\right\}\right], \\
\tilde{v}_{j}^{*} & =\left[\tilde{v}_{j}^{L *}, \tilde{v}_{j}^{U *}\right]=\left[\min _{i}\left\{\tilde{v}_{i j}^{L}\right\}, \min _{i}\left\{\tilde{v}_{i j}^{U}\right\}\right], \\
\tilde{\pi}_{j}^{*} & =\left[\tilde{\pi}_{j}^{L *}, \tilde{\pi}_{j}^{U *}\right], \quad \tilde{\pi}_{j}^{L *}=1-\tilde{\mu}_{j}^{U *}-\tilde{v}_{j}^{U *}, \quad \tilde{\pi}_{j}^{U *}=1-\tilde{\mu}_{j}^{L *}-\tilde{v}_{j}^{L *}, \\
i & =1,2, \ldots, m ; j=1,2, \ldots, n .
\end{aligned}
$$

Step 3. Calculate the weighted projection of the alternative $A_{i}(i=1,2, \ldots, m)$ on the the UIFIS $\tilde{A}^{*}$ by $(26)$ :

$$
\operatorname{Pr} j_{\tilde{A}^{*}} A_{i}=\frac{\sum_{j=1}^{n} w_{j}^{2}\left(\tilde{\mu}_{i j}^{L} \tilde{\mu}_{j}^{L *}+\tilde{\mu}_{i j}^{U} \tilde{\mu}_{j}^{U *}+\tilde{v}_{i j}^{L} \tilde{v}_{j}^{L *}+\tilde{v}_{i j}^{U} \tilde{v}_{j}^{U *}+\tilde{\pi}_{i j}^{L} \tilde{\pi}_{j}^{L *}+\tilde{\pi}_{i j}^{U} \tilde{\pi}_{j}^{U *}\right)}{\left|\tilde{A}^{*}\right|_{w}} .
$$

Step 4. Rank all the alternatives $A_{i}(i=1,2, \ldots, m)$ in accordance with the weighted projection $\operatorname{Pr} j_{\tilde{A}^{*}} A_{i}$. The larger the weighted projection $\operatorname{Pr} j_{\tilde{A}^{*}} A_{i}$, the closer the alternative 
$A_{i}$ is to the UIFIS $\tilde{A}^{*}$, and the better the alternative, $A_{i}$. Therefore, all the alternatives can be ranked according to the values of the weighted projection so that the best alternative can be selected.

\section{Illustrative Example}

Now, we discuss a problem concerning with a manufacturing company, searching the best global supplier for one of its most critical parts used in assembling process. The attributes which are considered here in selection of five potential global suppliers, i.e., the set of alternatives is $A=\left(A_{1}, A_{2}, A_{3}, A_{4}, A_{5}\right)$, are: (1) $G_{1}$ : overall cost of the product; (2) $G_{2}$ : quality of the product; (3) $G_{3}$ : service performance of supplier; (4) $G_{4}$ : supplier's profile; and (5) $G_{5}$ : risk factor. An expert group is formed which consists of four experts from each strategic decision area. By statistical methods, the expert $e_{k}(k=1,2,3,4)$ evaluates the characteristics of the potential global supplier $A_{i}(i=1,2,3,4,5)$ with respect to the attribute $G_{j}(j=1,2,3,4,5)$ on the fuzzy concept "excellence". Thus the four decision matrices $R^{(k)}(k=1,2,3,4)$ can be obtained and expressed in the Tables $1-4$.

Table 1

Expert 1 - intuitionistic fuzzy decision matrix $R^{(1)}$.

\begin{tabular}{llllll}
\hline & $G_{1}$ & $G_{2}$ & $G_{3}$ & $G_{4}$ & $G_{5}$ \\
\hline$A_{1}$ & $(0.5,0.4,0.1)$ & $(0.5,0.3,0.2)$ & $(0.2,0.6,0.2)$ & $(0.4,0.4,0.2)$ & $(0.5,0.4,0.1)$ \\
$A_{2}$ & $(0.7,0.3,0)$ & $(0.3,0.3,0.4)$ & $(0.6,0.2,0.2)$ & $(0.5,0.4,0.1)$ & $(0.7,0.2,0.3)$ \\
$A_{3}$ & $(0.5,0.4,0.1)$ & $(0.6,0.4,0)$ & $(0.2,0.7,0.1)$ & $(0.5,0.3,0.2)$ & $(0.6,0.3,0.1)$ \\
$A_{4}$ & $(0.7,0.2,0.1)$ & $(0.3,0.6,0.1)$ & $(0.4,0.4,0.2)$ & $(0.4,0.5,0.1)$ & $(0.4,0.4,0.2)$ \\
$A_{5}$ & $(0.4,0.3,0.3)$ & $(0.5,0.4,0.1)$ & $(0.9,0.1,0)$ & $(0.3,0.7,0)$ & $(0.3,0.6,0.1)$ \\
\hline
\end{tabular}

Table 2

Expert 2 - intuitionistic fuzzy decision matrix $R^{(2)}$.

\begin{tabular}{llllll}
\hline & $G_{1}$ & $G_{2}$ & $G_{3}$ & $G_{4}$ & $G_{5}$ \\
\hline$A_{1}$ & $(0.5,0.5,0)$ & $(0.8,0.2,0)$ & $(0.6,0.2,0.2)$ & $(0.7,0.2,0.1)$ & $(0.6,0.3,0.1)$ \\
$A_{2}$ & $(0.4,0.5,0.1)$ & $(0.6,0.2,0.2)$ & $(0.7,0.3,0)$ & $(0.3,0.4,0.3)$ & $(0.7,0.1,0.2)$ \\
$A_{3}$ & $(0.5,0.3,0.2)$ & $(0.2,0.7,0.1)$ & $(0.8,0.1,0.1)$ & $(0.7,0.1,0.2)$ & $(0.2,0.8,0)$ \\
$A_{4}$ & $(0.6,0.2,0.2)$ & $(0.3,0.5,0.2)$ & $(0.5,0.5,0)$ & $(0.9,0.1,0)$ & $(0.4,0.5,0.1)$ \\
$A_{5}$ & $(0.1,0.8,0.1)$ & $(0.5,0.4,0.1)$ & $(0.3,0.6,0.1)$ & $(0.4,0.3,0.3)$ & $(0.7,0.2,0.1)$ \\
\hline
\end{tabular}

Table 3

Expert 3 - intuitionistic fuzzy decision matrix $R^{(3)}$.

\begin{tabular}{llllll}
\hline & $G_{1}$ & $G_{2}$ & $G_{3}$ & $G_{4}$ & $G_{5}$ \\
\hline$A_{1}$ & $(0.5,0.3,0.2)$ & $(0.7,0.2,0.1)$ & $(0.5,0.3,0.2)$ & $(0.5,0.4,0.1)$ & $(0.7,0.3,0)$ \\
$A_{2}$ & $(0.6,0.3,0.1)$ & $(0.6,0.2,0.2)$ & $(0.7,0.2,0.1)$ & $(0.8,0.1,0.1)$ & $(0.5,0.4,0.1)$ \\
$A_{3}$ & $(0.7,0.3,0)$ & $(0.4,0.4,0.2)$ & $(0.6,0.3,0.1)$ & $(0.2,0.7,0.1)$ & $(0.6,0.3,0.1)$ \\
$A_{4}$ & $(0.4,0.5,0.1)$ & $(0.6,0.2,0.2)$ & $(0.4,0.6,0)$ & $(0.7,0.2,0.1)$ & $(0.6,0.2,0.2)$ \\
$A_{5}$ & $(0.7,0.2,0.1)$ & $(0.7,0.3,0)$ & $(0.6,0.1,0.3)$ & $(0.7,0.3,0)$ & $(0.5,0.3,0.2)$ \\
\hline
\end{tabular}


Table 4

Expert 4 - intuitionistic fuzzy decision matrix $R^{(4)}$.

\begin{tabular}{llllll}
\hline & $G_{1}$ & $G_{2}$ & $G_{3}$ & $G_{4}$ & $G_{5}$ \\
\hline$A_{1}$ & $(0.4,0.5,0.1)$ & $(0.3,0.6,0.1)$ & $(0.6,0.2,0.2)$ & $(0.4,0.5,0.1)$ & $(0.7,0.2,0.1)$ \\
$A_{2}$ & $(0.7,0.2,0.1)$ & $(0.4,0.6,0)$ & $(0.2,0.7,0.1)$ & $(0.6,0.2,0.2)$ & $(0.5,0.4,0.1)$ \\
$A_{3}$ & $(0.4,0.4,0.2)$ & $(0.2,0.8,0)$ & $(0.6,0.2,0.2)$ & $(0.5,0.4,0.1)$ & $(0.9,0.1,0)$ \\
$A_{4}$ & $(0.4,0.5,0.1)$ & $(0.7,0.2,0.1)$ & $(0.6,0.3,0.1)$ & $(0.3,0.5,0.2)$ & $(0.4,0.5,0.1)$ \\
$A_{5}$ & $(0.4,0.6,0)$ & $(0.5,0.4,0.1)$ & $(0.2,0.8,0)$ & $(0.5,0.4,0.1)$ & $(0.3,0.6,0.1)$ \\
\hline
\end{tabular}

Table 5

Expert 1 - intuitionistic fuzzy decision matrix $D^{(1)}$.

\begin{tabular}{llllll}
\hline & $G_{1}$ & $G_{2}$ & $G_{3}$ & $G_{4}$ & $G_{5}$ \\
\hline$A_{1}$ & $(0.4,0.5,0.1)$ & $(0.5,0.3,0.2)$ & $(0.2,0.6,0.2)$ & $(0.4,0.4,0.2)$ & $(0.4,0.5,0.1)$ \\
$A_{2}$ & $(0.3,0.7,0)$ & $(0.3,0.3,0.4)$ & $(0.6,0.2,0.2)$ & $(0.5,0.4,0.1)$ & $(0.2,0.7,0.3)$ \\
$A_{3}$ & $(0.4,0.5,0.1)$ & $(0.6,0.4,0)$ & $(0.2,0.7,0.1)$ & $(0.5,0.3,0.2)$ & $(0.3,0.6,0.1)$ \\
$A_{4}$ & $(0.2,0.7,0.1)$ & $(0.3,0.6,0.1)$ & $(0.4,0.4,0.2)$ & $(0.4,0.5,0.1)$ & $(0.4,0.4,0.2)$ \\
$A_{5}$ & $(0.3,0.4,0.3)$ & $(0.5,0.4,0.1)$ & $(0.9,0.1,0)$ & $(0.3,0.7,0)$ & $(0.6,0.3,0.1)$ \\
\hline
\end{tabular}

Table 6

Expert 2 - intuitionistic fuzzy decision matrix $D^{(2)}$.

\begin{tabular}{llllll}
\hline & $G_{1}$ & $G_{2}$ & $G_{3}$ & $G_{4}$ & $G_{5}$ \\
\hline$A_{1}$ & $(0.5,0.5,0)$ & $(0.8,0.2,0)$ & $(0.6,0.2,0.2)$ & $(0.7,0.2,0.1)$ & $(0.3,0.6,0.1)$ \\
$A_{2}$ & $(0.5,0.4,0.1)$ & $(0.6,0.2,0.2)$ & $(0.7,0.3,0)$ & $(0.3,0.4,0.3)$ & $(0.1,0.7,0.2)$ \\
$A_{3}$ & $(0.3,0.5,0.2)$ & $(0.2,0.7,0.1)$ & $(0.8,0.1,0.1)$ & $(0.7,0.1,0.2)$ & $(0.8,0.2,0)$ \\
$A_{4}$ & $(0.2,0.6,0.2)$ & $(0.3,0.5,0.2)$ & $(0.5,0.5,0)$ & $(0.9,0.1,0)$ & $(0.5,0.4,0.1)$ \\
$A_{5}$ & $(0.8,0.1,0.1)$ & $(0.5,0.4,0.1)$ & $(0.3,0.6,0.1)$ & $(0.4,0.3,0.3)$ & $(0.2,0.7,0.1)$ \\
\hline
\end{tabular}

Table 7

Expert 3 - intuitionistic fuzzy decision matrix $D^{(3)}$

\begin{tabular}{llllll}
\hline & $G_{1}$ & $G_{2}$ & $G_{3}$ & $G_{4}$ & $G_{5}$ \\
\hline$A_{1}$ & $(0.3,0.5,0.2)$ & $(0.7,0.2,0.1)$ & $(0.5,0.3,0.2)$ & $(0.5,0.4,0.1)$ & $(0.3,0.7,0)$ \\
$A_{2}$ & $(0.3,0.6,0.1)$ & $(0.6,0.2,0.2)$ & $(0.7,0.2,0.1)$ & $(0.8,0.1,0.1)$ & $(0.4,0.5,0.1)$ \\
$A_{3}$ & $(0.3,0.7,0)$ & $(0.4,0.4,0.2)$ & $(0.6,0.3,0.1)$ & $(0.2,0.7,0.1)$ & $(0.3,0.6,0.1)$ \\
$A_{4}$ & $(0.5,0.4,0.1)$ & $(0.6,0.2,0.2)$ & $(0.4,0.6,0)$ & $(0.7,0.2,0.1)$ & $(0.2,0.6,0.2)$ \\
$A_{5}$ & $(0.2,0.7,0.1)$ & $(0.7,0.3,0)$ & $(0.6,0.1,0.3)$ & $(0.7,0.3,0)$ & $(0.3,0.5,0.2)$ \\
\hline
\end{tabular}

Considering that the attributes have two different types, we first transform the attribute values of cost type into the attribute values of benefit type by using (10), then $R^{(k)}=$ $\left(r_{i j}^{(k)}\right)_{m \times n}$ is transformed into $D^{(k)}=\left(d_{i j}^{(k)}\right)_{m \times n}$, respectively, shown in the Tables 5-8.

Thus, we can utilize the proposed method to obtain the most desirable alternative(s). We first utilize (13) to determine the expert weights for each evaluation value and aggregate the different experts' evaluations by (14). For example, the weights of the four experts for $A_{1}$ with respect to $G_{1}$ are $w_{11}^{(1)}=0.251, w_{11}^{(2)}=0.271, w_{11}^{(3)}=0.231, w_{11}^{(4)}=0.248$, 
Table 8

Expert 4 - intuitionistic fuzzy decision matrix $D^{(4)}$.

\begin{tabular}{llllll}
\hline & $G_{1}$ & $G_{2}$ & $G_{3}$ & $G_{4}$ & $G_{5}$ \\
\hline$A_{1}$ & $(0.5,0.4,0.1)$ & $(0.3,0.6,0.1)$ & $(0.6,0.2,0.2)$ & $(0.4,0.5,0.1)$ & $(0.2,0.7,0.1)$ \\
$A_{2}$ & $(0.2,0.7,0.1)$ & $(0.4,0.6,0)$ & $(0.2,0.7,0.1)$ & $(0.6,0.2,0.2)$ & $(0.4,0.5,0.1)$ \\
$A_{3}$ & $(0.4,0.4,0.2)$ & $(0.2,0.8,0)$ & $(0.6,0.2,0.2)$ & $(0.5,0.4,0.1)$ & $(0.1,0.9,0)$ \\
$A_{4}$ & $(0.5,0.4,0.1)$ & $(0.7,0.2,0.1)$ & $(0.6,0.3,0.1)$ & $(0.3,0.5,0.2)$ & $(0.5,0.4,0.1)$ \\
$A_{5}$ & $(0.6,0.4,0)$ & $(0.5,0.4,0.1)$ & $(0.2,0.8,0)$ & $(0.5,0.4,0.1)$ & $(0.6,0.3,0.1)$ \\
\hline
\end{tabular}

Table 9

Collective decision matrix $D$.

\begin{tabular}{llllll}
\hline & $G_{1}$ & $G_{2}$ & $G_{3}$ & $G_{4}$ & $G_{5}$ \\
\hline$A_{1}$ & $(0.43,0.47,0.1)$ & $(0.65,0.27,0.08)$ & $(0.51,0.28,0.21)$ & $(0.53,0.35,0.12)$ & $(0.30,0.62,0.08)$ \\
$A_{2}$ & $(0.33,0.60,0.07)$ & $(0.50,0.29,0.21)$ & $(0.61,0.28,0.11)$ & $(0.62,0.22,0.16)$ & $(0.28,0.60,0.12)$ \\
$A_{3}$ & $(0.35,0.52,0.13)$ & $(0.37,0.56,0.07)$ & $(0.63,0.23,0.14)$ & $(0.52,0.29,0.19)$ & $(0.45,0.51,0.04)$ \\
$A_{4}$ & $(0.36,0.51,0.13)$ & $(0.52,0.32,0.16)$ & $(0.48,0.44,0.08)$ & $(0.72,0.23,0.05)$ & $(0.41,0.44,0.15)$ \\
$A_{5}$ & $(0.58,0.30,0.13)$ & $(0.57,0.37,0.06)$ & $(0.68,0.22,0.1)$ & $(0.51,0.40,0.09)$ & $(0.46,0.42,0.12)$ \\
\hline
\end{tabular}

respectively, and then we can obtain

$$
d_{11}=w_{11}^{(1)} d_{11}^{(1)}+w_{11}^{(2)} d_{11}^{(2)}+w_{11}^{(3)} d_{11}^{(3)}+w_{11}^{(4)} d_{11}^{(4)}=(0.43,0.47,0.1) .
$$

In the same way, we can get all the other values to form the following collective decision matrix $D=\left(d_{i j}\right)_{5 \times 5}$ (see Table 9).

Assume the attribute weighting vector $w=(0.16,0.23,0.18,0.32,0.12)^{T}$, then we employ (8) to calculate the weighted projection of the alternatives $A_{i}$ on the IFIS $A^{*}$ :

$$
\begin{array}{ll}
\operatorname{Pr} j_{A^{*} A_{1}}=0.301, & \operatorname{Pr} j_{A^{*} A_{2}}=0.300, \\
\operatorname{Pr} j_{A^{*} A_{4}}=0.320, & \operatorname{Pr} j_{A^{*} A_{1}}=0.307 .
\end{array}
$$

Since

$$
\operatorname{Pr} j_{A^{*}} A_{4}>\operatorname{Pr} j_{A^{*}} A_{5}>\operatorname{Pr} j_{A^{*}} A_{2}>\operatorname{Pr} j_{A^{*}} A_{1}>\operatorname{Pr} j_{A^{*}} A_{3} .
$$

Then

$$
A_{4} \succ A_{5} \succ A_{2} \succ A_{1} \succ A_{3},
$$

where " $\succ$ " indicates the relation "superior to" or "preferred to", hence, the most desirable alternative is $\mathrm{A}_{4}$.

From the above example, we can see that, the weights of the experts can be deduced from the decision matrices and different attributes have different weights. This can avoid the affect of unfair evaluation values. For example, the weights to $r_{11}^{(1)}=(0.4,0.5,0.1)$, $r_{11}^{(2)}=(0.5,0.5,0), r_{11}^{(3)}=(0.3,0.5,0.2)$ and $r_{11}^{(4)}=(0.5,0.4,0.1)$ are $w_{11}^{(1)}=0.251$, 
$w_{11}^{(2)}=0.271, w_{11}^{(3)}=0.231$ and $w_{11}^{(4)}=0.248$, respectively. $r_{11}^{(2)}$ is the one closest to the mean value, so it has the largest weight, and $r_{11}^{(3)}$ is the one farthest from the mean value, so it has the smallest weight. Similarly, the weights to $r_{12}^{(1)}=(0.5,0.3,0.2)$, $r_{12}^{(2)}=(0.8,0.2,0), r_{12}^{(3)}=(0.7,0.2,0.1)$ and $r_{12}^{(4)}=(0.3,0.6,0.1)$ are $w_{12}^{(1)}=0.274$, $w_{12}^{(2)}=0.220, w_{12}^{(3)}=0.246$ and $w_{12}^{(4)}=0.260$, respectively. The expert $e_{2}$ may be unfamiliar with the attribute $G_{2}$, a low evaluation is given, hence the weight of $r_{12}^{(2)}$ is the smallest because it is the one farthest from the mean value. In addition, the method for ranking and selecting alternatives proposed by the Algorithm 1 is very simple and convenient to use in practical applications.

If we utilize the IFWA (Xu, 2007a) operator

$$
d_{i}=I F W A\left(d_{i 1}, d_{i 2}, \ldots, d_{i n}\right)=w_{1} d_{i 1}+w_{2} d_{i 2}+\cdots+w_{n} d_{i n}, \quad i=1,2, \ldots, 5
$$

to derive the collective overall preference value $d_{i}(i=1,2, \ldots, 5)$ of the alternative $A_{i}$ in the collective intuitionistic fuzzy decision matrix $D=\left(d_{i j}\right)_{5 \times 5}$, where $w=$ $(0.16,0.23,0.18,0.32,0.12)^{T}$ is the weighting vector of the attribute, then we have

$$
\begin{array}{ll}
d_{1}=(0.53,0.35,0.12), & d_{2}=(0.52,0.32,0.16), \quad d_{3}=(0.48,0.38,0.14), \\
d_{4}=(0.56,0.34,0.10), & d_{5}=(0.57,0.33,0.10) .
\end{array}
$$

To rank the IFN, several relevant approaches have been presented, see, for instance, Chen and Tan (1994), Hong and Choi (2000), Liu and Wang (2007), Xu (2007a), and Szmidt and Kacprzyk (2008, 2009). Among the existing ranking techniques, Szmidt and Kacprzyk's $(2008,2009)$ new ranking approach for IFNs takes into account not only the amount of information (both positive and negative) associated with an alternative but also the reliability of information represented by an alternative indicating how sure the information is, we may use it here to evaluate the IFN $d_{i}(i=1,2, \ldots, 5)$, i.e.,

$$
S_{\mathrm{IFN}}\left(d_{i}\right)=0.5\left(1+\pi_{i}\right) d_{\mathrm{IFN}}\left(d_{i}, \alpha_{i}^{*}\right)
$$

where $\pi_{i}$ is the intuitionistic fuzzy index (or hesitation margin) of $d_{i}, \alpha_{i}^{*}=(1,0,0)$ is the ideal positive intuitionistic fuzzy alternative, and $d_{\mathrm{IFN}}(\cdot, \cdot)$ denotes the normalized Hamming distance between IFNs, i.e.,

$$
d_{\mathrm{IFN}}\left(\alpha_{1}, \alpha_{2}\right)=\frac{1}{2}\left(\left|\mu_{\alpha_{1}}-\mu_{\alpha_{2}}\right|+\left|v_{\alpha_{1}}-v_{\alpha_{2}}\right|+\left|\pi_{\alpha_{1}}-\pi_{\alpha_{2}}\right|\right)
$$

where $\alpha_{1}=\left(\mu_{\alpha_{1}}, v_{\alpha_{1}}, \pi_{\alpha_{1}}\right)$ and $\alpha_{2}=\left(\mu_{\alpha_{2}}, v_{\alpha_{2}}, \pi_{\alpha_{2}}\right)$ are two IFNs.

Szmidt and Kacprzyk $(2008,2009)$ pointed out that the measure $S_{\text {IFN }}\left(d_{i}\right)$ from (36) could rationally demonstrate the quality of an alternative; in other words, the lower values of $S_{\mathrm{IFN}}\left(d_{i}\right)$, the better the corresponding alternatives $A_{i}$. 
Finally, use (36) to calculate the measure $S_{\mathrm{IFN}}$ of $d_{i}(i=1,2, \ldots, 5)$ as follows:

$$
\begin{aligned}
& S_{\mathrm{IFN}}\left(d_{1}\right)=0.267, \quad S_{\mathrm{IFN}}\left(d_{2}\right)=0.275, \quad S_{\mathrm{IFN}}\left(d_{3}\right)=0.295, \\
& S_{\mathrm{IFN}}\left(d_{4}\right)=0.240, \quad S_{\mathrm{IFN}}\left(d_{5}\right)=0.236 .
\end{aligned}
$$

According to $S_{\mathrm{IFN}}\left(d_{i}\right)(i=1,2, \ldots, 5)$, we can easily rank all of the alternatives: $A_{5} \succ$ $A_{4} \succ A_{1} \succ A_{2} \succ A_{3}$, and hence, the best choice is $A_{5}$. As we can see, depending on different methods used, the results may be different.

Similarly, if the preferences given by the experts are expressed in interval intuitionistic fuzzy decision matrices, then we can utilize the Algorithm 2 to derive the weights of the experts.

\section{Conclusions}

The existing MAGDM approaches based on IFS or IVIFS can only cope with the situation that the weights of the experts are determined beforehand and the weights of the decision makers are the same for all the attributes. In this paper, we have developed a new algorithms in which the weights of the experts are derived from the decision matrices and decision makers have different weights for different attributes. The closer an evaluation value is to the ideal decision of the evaluation values, the larger the weight is, and the farther an evaluation value is from the ideal decision of the evaluation values, the smaller the weight is. These can effectively avoid the unreasonable evaluation values due to the lack of knowledge or limited experience of experts. Thus, the results are more reasonable. Then, we develop a straightforward and practical algorithm to rank alternatives based on the weighted projection of the alternative on the intuitionistic fuzzy ideal solution (IFIS). Furthermore, we have extended the developed models and procedures to deal with the MAGDM with interval-valued intuitionistic fuzzy information. Finally, numerical examples are given to further illustrate the practicality and efficiency of the new algorithms. Further studies could be aimed at devloping hybrid decision making methods based on different linguistic represenation methods (e.g. 2-dimensional uncertain linguistic information (Liu, 2012)) and fuzzy multi-crieria decision making methods (Zavadskas et al., 2012).

Acknowledgements. This paper is supported by the National Funds of Social Science of China (Nos. 12ATJ001, 12\&ZD211), Science Foundation of Ministry of Education of China (No. 13YJA910001), the Key Research Center of Philosophy and Social Science of Zhejiang Province - Modern Port Service Industry and Creative Culture Research Center, the MOE Project of Key Research Institute of Humanities and Social Sciences in Universities (No. 13JJD910002), Zhejiang Provincial Key Research Base for Humanities and Social Science Research (Statistics), Projects in Science and Technique of Ningbo Municipal (No. 2012B82003), Zhejiang Province Natural Science Foundation (No. Q12G030068), Ningbo Natural Science Foundation (No. 2013A610286) and Projects of Federation of Social Sciences Research in Zhejiang Province (No. 2013B069). 


\section{References}

Atanassov, K.T. (1986). Intuitionistic fuzzy sets. Fuzzy Sets and Systems, 20, 87-96.

Atanassov, K. (1999). Intuitionistic Fuzzy Sets: Theory and Applications. Physica-Verlag, Heidelberg.

Atanassov, K., Gargov, G. (1989). Interval-valued intuitionistic fuzzy sets. Fuzzy Sets and Systems, 31, 343-349.

Atanassov, K.T., Pasi, G., Yager, R.R. (2005). Intuitionistic fuzzy interpretations of multi-criteria multi-person and multi-measurement tool decision making. International Journal of Systems Science, 36, 859-868.

Boran, F.E., Genc, S., Kurt, M., Akay, D. (2009). A multi-criteria intuitionistic fuzzy group decision making for supplier selection with TOPSIS method. Expert Systems with Applications, 36, 11363-11368.

Bustince, H., Burillo, P. (1996). Vague sets are intuitionistic fuzzy sets. Fuzzy Sets and Systems, 79, 403-405.

Chen, S.M., Tan, J.M. (1994). Handling multi-criteria fuzzy decision making problems based on vague set theory. Fuzzy Sets and Systems, 67, 163-172.

Gau, W.L., Buehrer, D.J. (1993). Vague sets. IEEE Transactions on Systems Man and Cybernetics, 23, $610-614$.

Gong, Z.W., Li, L.S., Zhou, F.X., Yai, T.X. (2009). Goal programming approaches to obtain the priority vectors from the intuitionistic fuzzy preference relations. Computers \& Industrial Engineering, 57, 1187-1193.

Grzegorzewski, P. (2004). Distances between intuitionistic fuzzy sets and/or interval-valued fuzzy sets based on the Hausdorff metric. Fuzzy Sets and Systems, 148, 319-328.

Lakshmana Gomathi Nayagam, V., Geetha, S. (2011). Ranking of interval-valued intuitionistic fuzzy sets. Applied Soft Computing, 11, 3368-3372.

Li, D.F. (2004). Some measures of dissimilarity in intuitionistic fuzzy structures. Journal of Computer and Systems Sciences, 68, 115-122.

Li, D.F. (2008). Extension of the LINMAP for multi-attribute decision making under Atanassov's intuitionistic fuzzy environment. Fuzzy Optimization and Decision Making, 7, 7-34.

Li, D.F. (2011). Closeness coefficient based nonlinear programming method for interval-valued intuitionistic fuzzy multiattribute decision making with incomplete preference information. Applied Soft Computing, 11, 3402-3418.

Li, D.F., Wang, Y.C., Liu, S., Shan, F. (2009). Fractional programming methodology for multi-attribute group decision-making using IFS. Applied Soft Computing, 9, 219-225

Li, D.F., Chen, G.H., Huang, Z.G. (2010). Linear programming method for multiattribute group decision making using IF sets. Information Sciences, 180, 1591-1609.

Lin, L., Yuan, X.H., Xia, Z.Q. (2007). Multicriteria fuzzy decision-making methods based on intuitionistic fuzzy sets. Journal of Computer and System Sciences, 73, 84-88.

Liou, J.J.H., Tzeng, G.H. (2012). Comments on "Multiple criteria decision making (MCDM) methods in economics: an overview". Technological and Economic Development of Economy, 18, 672-695.

Liu, H.W., Wang, G.J. (2007). Multi-attribute decision-making methods based on intuitionistic fuzzy sets. European Journal of Operational Research, 179, 220-233.

Liu, P.D. (2012). An approach to group decision making based on 2-dimension uncertain linguistic information. Technological and Economic Development of Economy, 18, 424-437.

Hong, D.H., Choi, C.H. (2000). Multicriteria fuzzy decision-making problems based on vague set theory. Fuzzy Sets and Systems, 114, 103-113.

Mitchell, H.B. (2004). An intuitionistic OWA operator. International Journal of Uncertainty, Fuzziness and Knowledge-Based Systems, 12, 843-860.

Szmidt, E., Kacprzyk, J. (2008). A new approach to ranking alternatives expressed via intuitionistic fuzzy sets. In: D. Ruan et al. (Eds.), Computational Intelligence in Decision and Control. World Scientific, Singapore, pp. 265-270.

Szmidt, E., Kacprzyk, J. (2009). Amount of information and its reliability in the ranking of Atanassov's intuitionistic fuzzy alternatives. In: E. Rakus-Andersson, et al. (Eds.), Recent Advances in Decision Making, vol. 222. Springer, Berlin, pp. 7-19.

Tan, C.Q. (2011). A multi-criteria interval-valued intuitionistic fuzzy group decision making with Choquet integral-based TOPSIS. Expert Systems with Applications, 38, 3023-3033.

Wang, Z.J., Xu, J.H., Wang, W.Z. (2009). Intuitionistic fuzzy multiple attribute group decision making based on projection method. In: Chinese Control and Decision Conference (CCDC 2009), pp. 2919-2924.

Wang, Z.J., Li, K.W., Xu, J.H. (2011). A mathematical programming approach to multi-attribute decision making with interval-valued intuitionistic fuzzy assessment information. Expert Systems with Applications, 38, $12462-12469$. 
Wei, G.W. (2008). Maximizing deviation method for multiple attribute decision making in intuitionistic fuzzy setting. Knowledge-Based Systems, 21, 833-836.

Wei, G.W. (2010a). GRA method for multiple attribute decision making with incomplete weight information in intuitionistic fuzzy setting. Knowledge-Based Systems, 23, 243-247.

Wei, G.W. (2010b). Some induced geometric aggregation operators with intuitionistic fuzzy information and their application to group decision making. Applied Soft Computing, 10, 423-431.

Xu, Z.S. (2007a). Intuitionistic fuzzy aggregation operators. IEEE Transactions on Fuzzy Systems, 15, 11791187.

Xu, Z.S. (2007b). Some similarity measures of intuitionistic fuzzy sets and their applications to multiple attribute decision making, Fuzzy Optimization and Decision Making, 6, 109-121.

Xu, Z.S. (2007c). Multi-person multi-attribute decision making models under intuitionistic fuzzy environment. Fuzzy Optimization and Decision Making, 6, 221-236.

$\mathrm{Xu}, \mathrm{Z}$.S. (2007d). Intuitionistic preference relations and their application in group decision making. Information Sciences, 177, 2363-2379.

Xu, Z.S. (2010a). A method based on distance measure for interval-valued intuitionistic fuzzy group decision making. Information Sciences, 180, 181-190.

Xu, Z.S. (2010b). A deviation-based approach to intuitionistic fuzzy multiple attribute group decision making. Group Decision and Negotiation, 19, 57-76.

Xu, Z.S., Cai, X.Q. (2010). Nonlinear optimization models for multiple attribute group decision making with intuitionistic fuzzy information. International Journal of Intelligent Systems, 25, 489-513.

Xu, Z.S., Hu, H. (2010). Projection models for intuitionistic fuzzy multiple attribute decision making. International Journal of Information Technology and Decision Making, 9, 267-280.

Xu, Y.J., Wang, H.M. (2012) The induced generalized aggregation operators for intuitionistic fuzzy sets and their application in group decision making. Applied Soft Computing, 12, 1168-1179.

Xu, Z.S., Yager, R.R. (2006). Some geometric aggregation operators based on intuitionistic fuzzy sets. International Journal of General Systems, 35, 417-433.

Xu, Z.S., Yager, R.R. (2008). Dynamic intuitionistic fuzzy multi-attribute decision making. Internation Journal of Approximate Reasoning, 48, 246-262.

Xu, Z.S., Yager, R.R. (2009). Intuitionistic and interval-valued intutionistic fuzzy preference relations and their measures of similarity for the evaluation of agreement within a group. Fuzzy Optimization and Decision Making, 8, 123-139.

Ye, J. (2009). Multicriteria fuzzy decision-making method based on a novel accuracy function under intervalvalued intuitionistic fuzzy environment. Expert Systems with Applications, 36, 6899-6902.

Ye, J. (2010) Fuzzy decision-making method based on the weighted correlation coefficient under intuitionistic fuzzy environment. European Journal of Operational Research, 205, 202-204.

Yue, Z.L. (2011a). Deriving decision maker's weights based on distance measure for interval-valued intuitionistic fuzzy group decision making. Expert Systems with Applications, 9, 11665-11670.

Yue, Z.L. (2011b). An extended TOPSIS for determining weights of decision makers with interval numbers. Knowledge-Based Systems, 24, 146-153.

Yue, Z.L. (2012a). Approach to group decision making based on determining the weights of experts by using projection method. Applied Mathematical Modelling, 38, 2900-2910.

Yue, Z.L. (2012b). Application of the projection method to determine weights of decision makers for group decision making, Scientia Iranica, 19, 872-878

Yue, Z.L., Jia, Y.Y., Ye, G.D. (2009). An approach for multiple attribute group decision making based on intuitionistic fuzzy information. International Journal of Uncertainty, Fuzziness and Knowledge-Based Systems, $17,317-332$.

Zadeh, L.A. (1965). Fuzzy sets. Information and Control, 8, 338-353.

Zavadskas, E.K., Fouladgar, M.M., Yazdani-Chamzini, A., Yakhchali, S.H., Ghasempourabadi, M.H. (2012). Project portfolio selection using fuzzy AHP and VIKOR techniques. Transformations in Business \& Economics, 11, 213-231.

Zeng, S.Z. (in press). Some intuitionistic fuzzy weighted distance measures and their application to group decision making. Group Decision and Negotiation (in press) doi:10.1007/s10726-011-9262-6.

Zeng, S.Z., Su, W.H. (2011). Intuitionistic fuzzy ordered weighted distance operator. Knowledge-Based Systems, 24, 1224-1232.

Zhao, H., Xu, Z.S., Ni, M.F., Liu, S.S. (2010). Generalized aggregation operators for intuionistic fuzzy sets. Internation Journal of Intelligent Systems, 25, 1-30. 
S.Z. Zeng graduated from the Tianjin University and obtained the master degree in applied mathematics in 2007. At present, he is studying his in-service doctor of applied statistics at Zhejiang Gongshang University. He has published more than 40 papers in journals, books and conference proceedings including journals such as Statistics Research, Economic Research, Knowledge-Based Systems and Group Decision and Negotiation. His main research fields are aggregation operators, decision making, comprehensive evaluation, and uncertainty. Now he is a full-time lecturer at Zhejiang Wanli University.

T. Baležentis is a Specialist at the Lithuanian Institute of Agrarian Economics. He received Student scientific paper award (2011) from the Lithuanian Academy of Sciences and President of the Republic of Lithuania A. Brazauskas scholarship for 2012-2013. T. Baležentis has published over 40 peer-reviewed papers on multi-criteria decision making, benchmarking, and agricultural economics.

J. Chen graduated from the Zhejiang Gongshang University and obtained the doctor degree in applied economics in 2010. He has published more than 30 papers in journals, books and conference proceedings including such journals as Statistics Research, Economic Research and Decision Making. His main research fields are group decision making and multi-attribute decision making. Now he is an associate professor of applied statistics at Zhejiang Gongshang University.

G.F. Luo graduated from the Zhejiang Gongshang University and obtained a bachelor degree in applied economics in 2011. At present, she is studying her doctor degree in statistics at Zhejiang Gongshang University. Her main research fields are decision making, comprehensive evaluation, and income distribution.

\title{
Projekcijos metodas grupiniam daugiakakriteriniam sprendimų pri- ėmimui su intuityvia neraiškiaja informacija
}

\author{
Shouzhen ZENG, Tomas BALEŽENTIS, Ji CHEN, Gangfei LUO
}

Straipsnyje nagrinejjamos intuityvaus neraiškiojo sprendimų prièmimo problemos, kuomet informacija apie nagrinejjamas alternatyvas yra išreiškiama intuityviais neraiškiaisiais skaičiais, o ekspertams suteikiami svoriai iš anksto nèra žinomi. Pasiūlyti ekspertams suteikiamų svorių ir alternatyvų pirmenybiu eilès nustatymo metodai, paremti projekcijos modeliais. Pirmiausia nustatomi ekspertų svoriai pagal atitinkamų ịverčių (sprendimų) projekcijas ị idealụjị ịvertị. Taigi, ekspertams suteikiami didesni svoriai, jei jų pateikti įverčiai labiau sutampa su idealiuoju ịverčiu, ir atvirkščiai. Tuomet nagrinejjamos alternatyvos ranguojamos pagal jų projekcijas į idealiąą alternatyvą. Minètas algoritmas pritaikytas ir intervaliniams intuityviems neraiškiesiems duomenims. Pateiktas praktinis sprendimų prièmimo pavyzdys atskleidžia metodo praktiškumą ir veiksmingumą. 